\title{
Um museu em chamas: o caso do Museu Nacional do Rio de Janeiro
}

\author{
Murilo Bastos da Cunha \\ Universidade de Brasília, Faculdade de Ciência da Informação, Brasília, DF, Brasil \\ murilobc@unb.br
}

DOI: https://doi.org/10.26512/rici.v12.n1.2019.19354

Resumo: O editorial comenta a tragédia ocorrida com o incêndio do Museu Nacional no Rio de Janeiro, que destruiu a mais antiga instituição científica brasileira e o museu mais antigo do país. Com um acervo de 20 milhões de peças, o Museu Nacional, localizado no Rio de Janeiro, foi criado por D. João VI e completou 200 anos em 2018. O edifício é tombado pelo patrimônio histórico e foi residência da família Real e Imperial brasileira. Enfatiza a necessidade de maior apoio às atividades museológicas no Brasil. Além disso, são comentados os artigos incluídos no primeiro número de 2019 da Revista IberoAmericana de Ciência da Informação.

Palavras-chave: Brasil. Museologia. Museu Nacional (Rio de Janeiro). museus.

\section{A museum on fire: the case of the National Museum of Rio de Janeiro}

Abstract: The editorial comments on the tragedy that occurred with the fire of the National Museum in Rio de Janeiro, which destroyed the oldest Brazilian scientific institution and the oldest museum in the country. With a collection of 20 million pieces, the National Museum, located in in Rio de Janeiro, was created by D. João VI and celebrated 200 years in 2018. The building is listed by historical patrimony and was the residence of the Brazilian Royal and Imperial family. Emphasizes the need for greater support for museum activities in Brazil. In addition, the articles included in the first issue of 2019 of the IberoAmerican Journal of Information Science are commented on.

Keywords: Brazil. Museology. museums. National Museum (Rio de Janeiro).

\section{Un museo en llamas: el caso del Museo Nacional de Río de Janeiro}

Resumen: El editorial comenta sobre la tragedia que ocurrió con el incendio del Museo Nacional en Río de Janeiro, que destruyó la institución científica brasileña más antigua y el museo más antiguo del país. Con una colección de 20 millones de piezas, el Museo Nacional, ubicado en Río de Janeiro, fue creado por D. João VI y se celebró 200 años en 2018. El edificio está catalogado por patrimonio histórico y fue la residencia de la familia real e imperial brasileña. Enfatiza la necesidad de un mayor apoyo para las actividades de los museos en Brasil. Además, se comentan los artículos incluidos en el primero número de 2019 de la Revista Iberoamericana de Ciencia de la Información.

Palabras-clave: Brasil. Museología. museos. Museo Nacional (Rio de Janeiro).

Caro leitor,

Um grande incêndio, que aconteceu durante a noite de domingo, 2 de setembro de 2018, destruiu a mais antiga instituição científica brasileira e o museu mais antigo do país. Com um acervo de 20 milhões de peças, o Museu Nacional, localizado na Quinta da Boa Vista, no Rio de Janeiro, foi criado por D. João VI e completou 200 anos em 2018. Tombado pelo patrimônio histórico o edifício foi residência da família Real e Imperial brasileira. O incêndio durou seis horas e sua causa é desconhecida. 
Este tipo de catástrofe já havia ocorrido em outras ocasiões. Em 2010, uma coleção de 80 mil espécies de répteis, a maior do país, foi queimada pelo fogo no Instituto Butantã. Cinco anos depois, o Museu da Língua Portuguesa, em São Paulo, foi completamente destruído em 2015.

O acontecido no Museu Nacional teve enorme repercussões no Brasil e no exterior. Por exemplo, uma carta, subscritada por 21 renovados pesquisadores, publicada na revista Science, de 27 de setembro de 2018, faz um alerta à comunidade internacional quando afirmam que o "fogo que consumiu os arquivos históricos é uma metáfora do estado atual da ciência no país" (LACK, 2018, p. 1322-1323). Continuando os pesquisadores afirmaram que

\begin{abstract}
As extensas coleções de história natural do museu, meticulosamente acumuladas ao longo de mais de dois séculos, documentaram a mudança na identidade e distribuição das espécies ao longo do tempo, registraram a cultura e as línguas nativas dos habitantes sul-americanos e arquivaram a origem e o progresso histórico de uma nação. A magnitude dessa perda é impressionante - não apenas para o Brasil, mas para o mundo. $O$ avanço científico é baseado em blocos de construção do passado e, sem esses componentes, os cientistas ficam sem pontos de referência. As coleções de museus são a base sobre a qual reconhecemos a novidade cultural e científica à medida que nos esforçamos para entender e melhorar a condição humana, para avançar em nossa compreensão de como as peças da natureza surgiram e se encaixam e até mesmo para prever o futuro ecológico e evolutivo da biodiversidade do planeta. (...) Há alguma esperança entre as cinzas. Muitas das coleções biológicas, incluindo vertebrados, a maioria dos invertebrados marinhos e plantas, bem como livros raros foram poupados porque estavam em edifícios diferentes. Felizmente, nenhuma vida humana foi perdida.
\end{abstract}

Alexandra Almeida, editora da Revista FAPESP, aponta em seu editorial que o periódico publicou, em seu número de outubro de 2018, uma edição onde

apresenta um panorama do acervo e das atividades desenvolvidas no museu, e também de congêneres nacionais e no exterior, discutindo os seus problemas e possíveis caminhos para garantir a preservação das valiosas coleções e a sustentabilidade dessas instituições . (...) A guarda de um acervo demanda trabalho contínuo e multidisciplinar de conservação e preservação (...) Uma ferramenta importante é a digitalização. O Arquivo Histórico, a memória institucional do Museu Nacional, foi destruído pelo fogo, mas há planos para sua recomposição a partir de reproduções. A integridade dos edifícios que hospedam coleções é fundamental. A reconstrução do palácio precisará incorporar modernas técnicas de segurança, de forma a garantir a integridade das peças e dos visitantes. Essa discussão já vem sendo feita no Museu Paulista, fechado desde 2013. (ALMEIDA, 2018, grifo nosso).

\title{
A própria Constituição Federal (BRASIL. Constituição), em seus artigos 215 a 216-A, afirma
}

Art. 215. O Estado garantirá a todos o pleno exercício dos direitos culturais e acesso às fontes da cultura nacional, e apoiará e incentivará a valorização e a difusão das manifestações culturais. (...)

Art. 216. Constituem patrimônio cultural brasileiro os bens de natureza material e imaterial, tomados individualmente ou em conjunto, portadores de referência à identidade, à ação, à memória dos diferentes grupos formadores da sociedade brasileira (...) 
Art. 216-A. O Sistema Nacional de Cultura, organizado em regime de colaboração, de forma descentralizada e participativa, institui um processo de gestão e promoção conjunta de políticas públicas de cultura, democráticas e permanentes, pactuadas entre os entes da Federação e a sociedade, tendo por objetivo promover o desenvolvimento humano, social e econômico com pleno exercício dos direitos culturais.

A perda de tão importante patrimônio sensibilizou a todos. As coleções de museus são tesouros nacionais atemporais, que representam nossas histórias, culturas e conquistas científicas. Toda instituição e governo devem refletir e prestar atenção a esse momento triste. Precisamos investir e proteger nossos museus e acervos para o benefício da ciência e da sociedade em todo o mundo. Portanto, basta cumprir os preceitos constitucionais para que os museus possam ser protegidos, preservados e difundidos.

No primeiro número da RICl em 2019 foram selecionados para publicação dez artigos, um artigo de revisão e dois documentos.

Boa leitura e até o nosso próximo número!

\section{Referências}

ALMEIDA, Alexandra Ozorio. O lugar dos museus. Revista FAPESP, n. 272, outubro 2018. Disponível em: <http://revistapesquisa.fapesp.br/2018/10/22/o-lugar-dos-museus/> Acesso em: 10 de nov. 2018.

BRASIL. Constituição da República Federativa do Brasil de 1988. Disponível em: $<$ http://www.planalto.gov.br/ccivil 03/Constituicao/Constituicao.htm > Acesso em: 15 nov. 2018.

LACK of science support fails Brazil. Science, v. 361, n. 6409, p. 1322-1323, 28 Sept 2018. Disponível em: $<$ http://science.sciencemag.org/content/361/6409/1322.2> Acesso em: 29 de set. 2018. 